\title{
Intravenous immunoglobulin for the treatment of quetiapin-induced bullous pemphigoid in an HIV-infected patient
}

Cabete, J.; Santos, G.; Rocha Páris, F.; Serrão, V.; Fidalgo, A. Dermatology Department, Hospital de Santo António dos Capuchos - C.H.L.C., Lisbon, Portugal 


\section{Case Presentation}

- 48-year-old woman

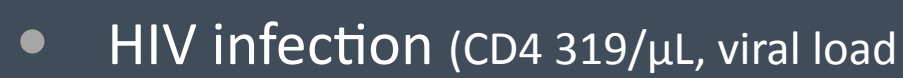
$<50 \mathrm{c} / \mathrm{mL}$ ), dementia, dyslipidemia

- Polymedicated (HAART, neuroleptics, statin)

- Bullous pemphigoid

- Light microscopy, DIF

- Persistent eosinophilia

- $\mathrm{P} P \mathrm{R}$

- Excluded autoimmune and paraneoplastic association

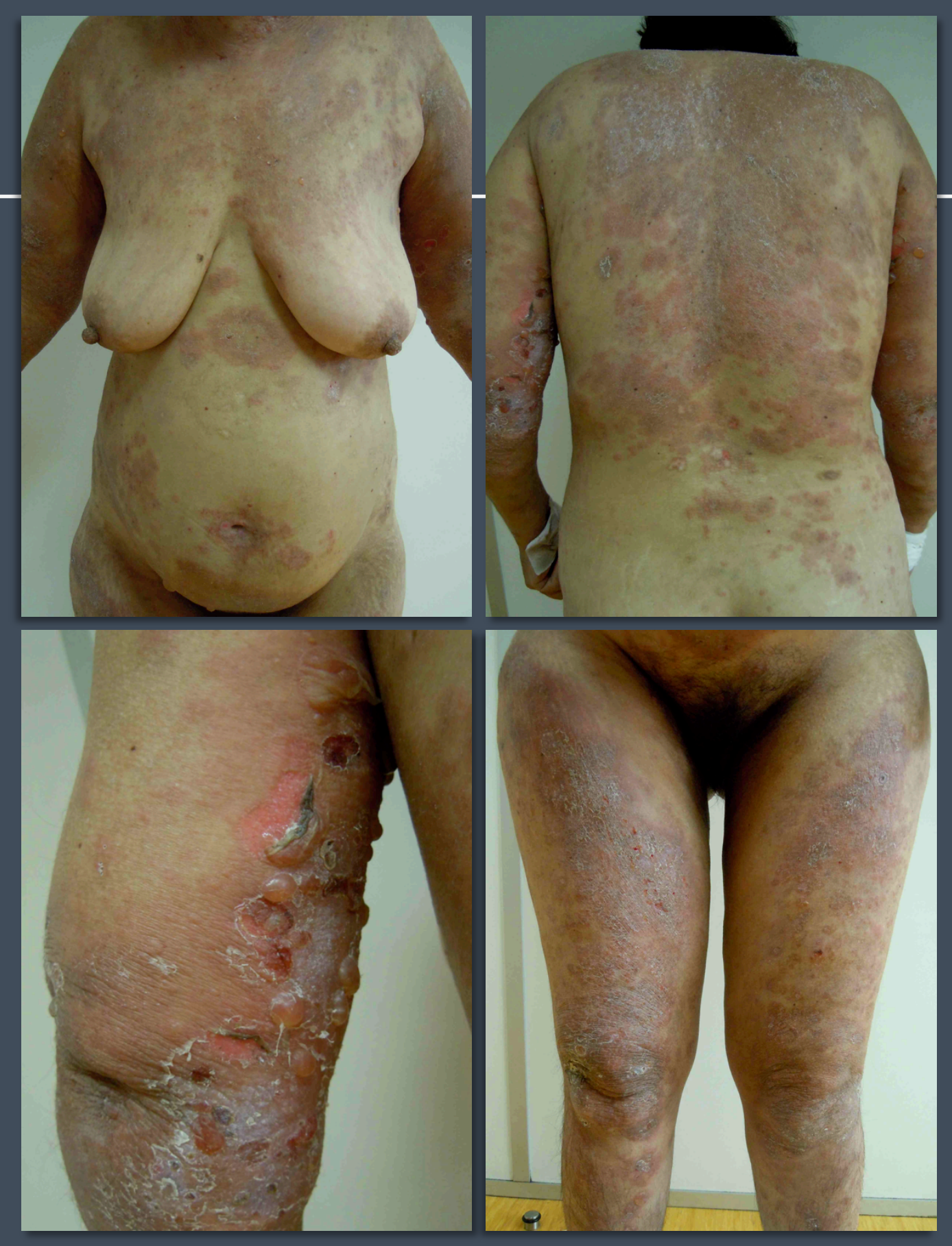




\section{Case Presentation}

\section{Treatment:}

Prednisolone $1 \mathrm{mg} / \mathrm{Kg} /$ day monotherapy

+ Azathioprine $100 \mathrm{mg} /$ day

+ IVIG 2 g/Kg/cycle (2-4 days), every 4wk

$\checkmark \quad$ Temporary disease control

$\checkmark \quad$ Well tolerated, no severe side-effects

but:

Refractory disease with corticosteroid tapering

Persistently elevated eosinophilia, and rising...
No response

No response + bicytopenia 


\section{Case Presentation}

Reviewing drug history:

- Quetiapine: the last introduced drug; $1200 \mathrm{mg} /$ day (above the maximum recommended daily dose)

- Quetiapine was discontinued

- Complete clinical resolution

- Resolution of eosinophilia

- Inadvertent rechallenge with olanzapine

- New flare and eosinophilia

- Complete sustained response with quetiapine/related drug withdrawal

- No need for immunosuppressors or immunomodulators 


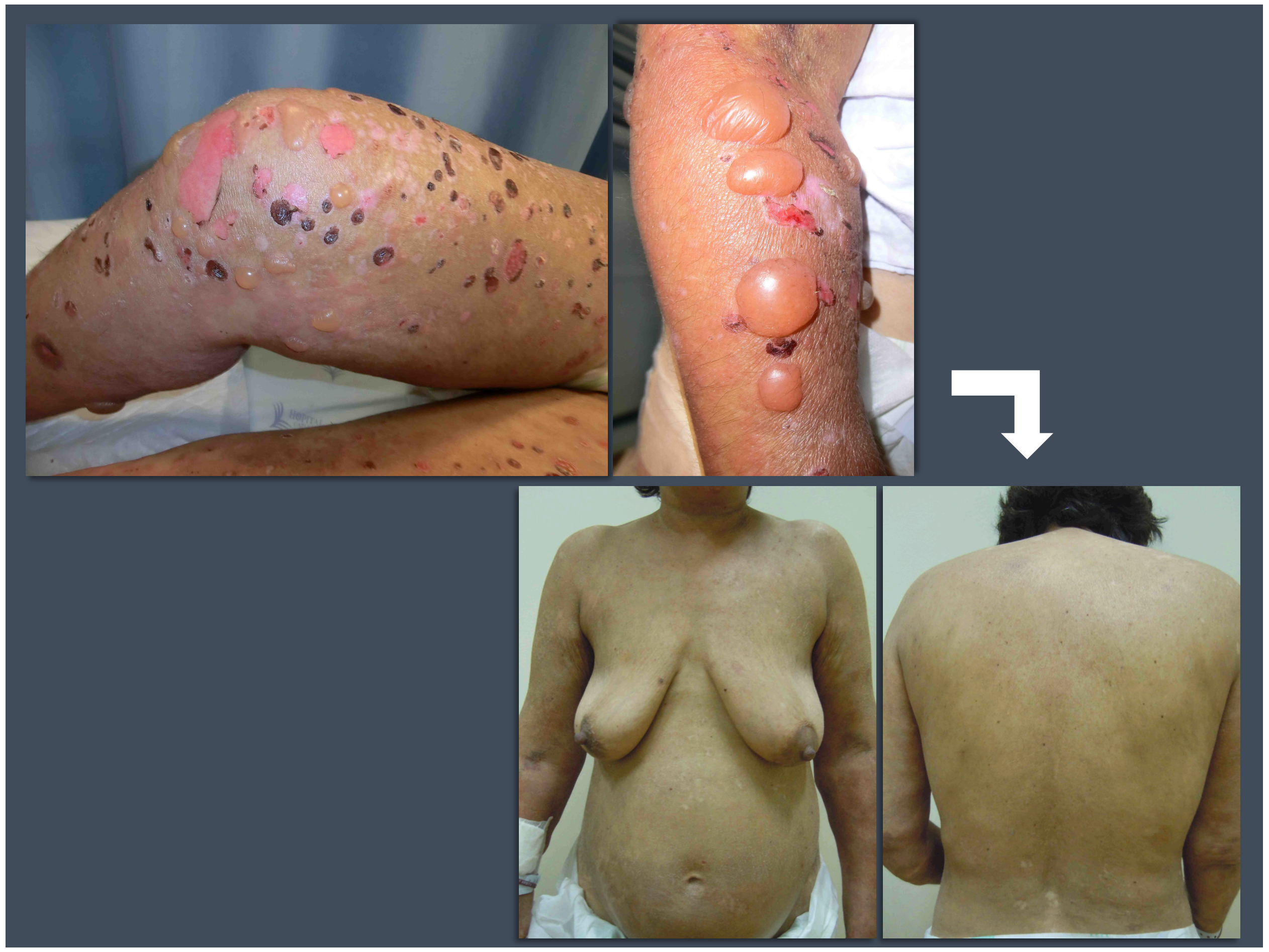




\section{Discussion}

1. Bullous pemphigoid in HIV patient

- HIV and autoimmunity: a disease continuum?

- Autoimmune diseases are common, but bullous pemphigoid is rare (4 cases)

2. Quetiapine-induced bullous pemphigoid

- Neuroleptics are associated with bullous pemphigoid

- Quetiapine: 1 previous report

3. IVIG in HIV patient

- An alternative to immunosuppression

- Widely used in other diseases in immunosuppressed patients 


\section{Conclusions:}

- This rare case of drug-induced bullous pemphigoid in an HIV patient suggests quetiapine as a drug trigger for this condition

- IGIV appears to be a safe and effective alternative to immunosuppressors in immunodeficient patients with severe bullous pemphigoid

- Safety, efficacy, and minimum effective dose studies in this subpopulation are warranted 


\section{References:}

- Zandman-Goddard G, Shoenfeld Y. HIV and autoimmunity. Autoimmun Rev. 2002;1(6):329-37.

- Stratton R, Slapak G, Mahungu T, Kinloch-de Loes S. Autoimmunity and HIV. Curr Opin Infect Dis. 2009;22(1):49-56.

- Russo S, Lopalco L. Is autoimmunity a component of natural immunity to HIV? Curr HIV Res. 2006 Apr;4(2):177-90.

- Bastuji-Garin S, Joly P, Picard-Dahan C, Bernard P, Vaillant L, Pauwels C, Salagnac V, Lok C, Roujeau JC. Drugs associated with bullous pemphigoid: A case-control study.Arch Dermatol. 1996;132(3):272-6.

- Sgouros DK, Christopoulos ND, Theodoropoulos K, et al. Drug-induced bullous pemphigoid: two case reports and review of the literature. Dermattikon. 2009, 3:63-8

- Langan SM, Groves RW, West J. The relationship between neurological disease and bullous pemphigoid: a populationbased case-control study. J Invest Dermatol. 2011;131(3):631-6.

- Gurcan HM, Jeph S, Ahmed AR. Immunoglobulin therapy in autoimmune mucocutaneous blistering diseases: a review of the evidence for its efficacy and safety. Am J Clin Dermatol. 2010;11(5):315-26.

- Chee SN, Murrell DF. The use of intravenous immunoglobulin in autoimmune bullous diseases. Immunol Allergy Clin North Am. 2012;32(2):323-30.

- Czernik A, Toosi S, Bystryn JC, Grando SA. Intravenous immunoglobulin in the treatment of autoimmune bullous dermatoses: an update. Autoimmunity. 2012;45(1):111-8.

- Tufan F, Kamali S, Erer B, Gul A, Inanc M, Ocal L, Konice M, Aral O. Safety of high-dose intravenous immunoglobulin in systemic autoimmune diseases. Clin Rheumatol. 2007;26(11):1913-5. 